\title{
EFFECTS OF TOBACCO SMOKING ON THE TOPOGRAPHIC EEG I
}

\author{
EDWARD F. DOMINO AND SHIGEAKI MATSUOKA
}

\author{
Department of Pharmacology, University of Michlgan \\ Ann Arbor, MI USA and \\ Department of Neurosurgery, University of Occupational and Environmental Health \\ Kitakyushu, Japan
}

(Final form, August 1993)

\begin{abstract}
Domino, Edward F, and Shigeaki Matsuoka. Effects of Tobaceo Smoking on the Topographic EEG I. Prog. Neuro-Psychopharmaco1. \& Bio1. Psychiat. 1994, 18(5):879-889.

1. The EEG and cardiovascular effects of smoking tobacco clgarettes of varying nicotine content were studied in Japanese chronic tobacco smokers.

2. Thirteen female and fifteen male adult normal volunteers were recruited for this study.

3. Each subject was asked to stop smoking the evening before coming to the laboratory the next morning, so they were approximately 10-12 hr deprived of cigarettes.

4. The objectives of this study were: a) To compare the mean differences in total activity in the alpha, alpha, beta, delta, and theta frequency bands before and after smoking a cigarette with $0,0,27,2.0$, and $2.16 \mathrm{mg}$ nicotine content in these 10-12 hr deprived tobacco smokers. b) To compare the topographic EEG patterns in such volunteers before and after smoking each of the above clgarettes. c) To compare the cardlovascular effects of smoking each of the above cigarettes in the same volunteers.
\end{abstract}

5. Smoking any of the four different types of cigarettes increased the total alpha EEG activity, although there were marked individual differences. Only after smoking nicotine containing eigarettes was there mean decrease in alpha $(8.0-9.8 \mathrm{~Hz})$ and an increase in $a l p h a_{2}(10-11.8 \mathrm{~Hz})$ activity in the EEG, not only in the occipital areas but also more diffusely throughout the cerebral cortex. There were no consistent mean changes in EEG delta, theta, or beta activity. Individual differences were marked, irrespective of the nicotine content of the cigarette smoked. Baseline state, individual subject variation, and nicotine content of the cigarette smoked determine the EEG effects observed. Zero nicotine cigarette smoking also caused EEG changes, including an increase in alpha and alpha activity.

6. In contrast to smoking a zero nicotine cigarette, the cardiovascular effects of tobacco smoking include a slight increase in heart rate, systolic, and diastolic blood pressure.

Keywards: acute cardiovascular effects of tobacco smoking, Japanese tobacco smokers, nicotine, plasma nicotine and cotinine, tobacco smoking abstinence $(10-12 \mathrm{br})$, topographic EEG. 
There have been many reports on the EEG effects of tobacco smoking involving subjects with variable periods of abstinence. Differences in experimental design, varying content of nicotine, etc. have contributed to a confusing number of conclusions, some of which are the exact opposite of others. In addition, a large varlety of EEG techniques have been used.

Motivation for the maintenance of the tobacco smoking habit still has not been elucidated. In 1988, the U.S, Surgeon General reported that nicotine is a highly addictive substance and is the basis for the tobacco smoking habit. Such a statement does not suggest any mechanism to explain why nicotine is reinforcing to some individuals. Edwards and Warburton (1982) expressed a concern for the lack of research using the topographic EEG. They stated that such research is necessary in order to understand the effects of tobacco smoking on different brain systems. The present investigation was designed to study the topographic EEG of adult Japanese tobacco smoking volunteers inasmuch as it is generally recognized that Japanese frequently smoke a large number of tobacco cigarettes. A preliminary abstract of this research was flrst presented by Domino and Matsuoka (1990) and is now being reported in detail.

\section{Methods}

\section{Subjects}

This study Involving experiments on human subjects was conducted under the guidelines of the Helsinki Declaration of 1975. Healthy adult male and female volunteers 21 to 61 years of age with a history of chronic (over one year) daily tobacco smoking and who inhaled were recruited for this study. Informed consent was obtained from all of the volunteers. Each subject was asked to stop smoking the evening before coming to the laboratory the next morning. Therefore, the subjects were deprived of smoking about 10-12 hr prior to being given a cigarette to smoke. Four different types of nonfiltered cigarettes were used. The subjects were unaware of which kind of cigarette they smoked.

Four separate groups of subjects were studied. The first group of six (four females, two males) smoked a nicotine free cigarette which contained a blend of orange, cocoa, and wheat leaves. The second group of seven (four females and three males) smoked a University of Kentucky low nicotine ( $0.27 \mathrm{mg}$ ) research cigarette (Lo3Al). The third group of ten (five females, flve males) smoked a University of Kentucky high nicotine $(2.16 \mathrm{mg}$ ) research clgarette (HI2R1). The fourth group of five males smoked a commercial tobacco ( $2.0 \mathrm{mg}$ nicotine) cigarette. Inasmuch as the research cigarettes were relatively old and stale, their content of nicotine was reanalyzed with the low nicotine cigarette $-0.3,25 \mathrm{mg}$ tar, and the high nicotine cigarette $-2.0 \mathrm{mg}$ and 32 mg tar consistent with their original analyses. The reanalysis of the nicotine and tar content was kindly provided by Dr. Tsutomu Ikeda, Manager, Scientific Information, Japen Tobacco Co., Tokyo, Japan. It should be noted that the (HI2R1) cigarette had 
an extremely high tar level that is not commercially avallable. In order to obtain resting EEG recordings, the subjects were asked to close their eyelids and relax before and after tobacco smoking.

\section{Equipment}

A Nihon Kohden 17 channel EEG, Model No. 4317, was used for recording the EEG data on line as well as on magnetic tape. A Sony data tape recording system, NFR-3000 series, Model No. DFR-3915, was used for recording 16 channels of EEG data. An Interface was provided by a Magatant Unit which allowed 16 channel recording on the 8 channel Sony tape recorder. Subsequently, the data were replayed from the tape recorder back through the EEG amplifiers to a Nihon Kohden ATAC 4540 frequency spectral analyzer. The topographic system used a total of 16 scalp electrodes to each ear as reference. EEG recordings were taken from $F_{p 1}, F_{p 2}, F_{3}, F_{7}, F_{2}, F_{4}, F_{8}, T_{3}, C_{3}, C_{2}, C_{4}$, $T_{4}, P_{1}, P_{2}, O_{1}, O_{2}$. The placenent of the scalp electrodes is shown in Fig 1 . Heart rate (Lead II, EKG) was recorded on the 17 th channel of the polygraph. Systemic arterial blood pressure was measured by auscultation. After baseline recordings, each subject volunteered to smoke one randomly assigned cigarette.

\section{Topographic BEG Analysis}

The topographic EEG data are based upon the voltages of a $6 \times 6 \mathrm{grid}$ of the top of the head. This technique has been developed by Ueno et al. (1975) and Matsuoka et al. (1979). In Fig 1 the black circles represent actual electrode sites and the open circles estimated sites.
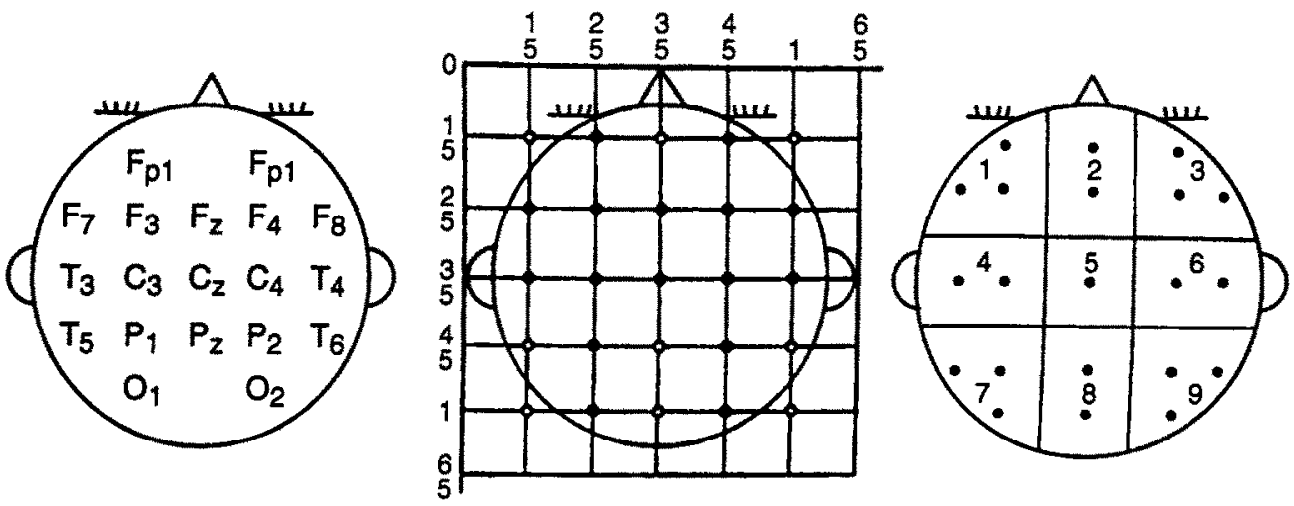

5762

Fig 1. Scalp electrode placements and derived grid used as the basis of the topographic EEG recordings.

A matrix printout of EEG data included a series of five vertical columns of which there are five values in each column of the derived EEG data in $\mu \mathrm{V} / 10$ sec intervals. The matrix data expressed in $\mu \mathrm{V} / 10 \mathrm{sec}$ represents the square root of the power (amplitude) for a given frequency band, either delta $(\delta)$, theta $(\theta), a l p h a_{1}\left(\alpha_{1}\right)$, alpha $\left(\alpha_{2}\right)$, or beta $(B)$. The entire matrix for a given frequency is also averaged to provide 
a mean \pm standard deviation. A single epoch of $10 \mathrm{sec}$ provides data for a total of 16 actual and 4 estimated racording sites in the topographic matrix for a given frequency band. The color distribution using the matrix data for topographic analysis is based upon a calibration voltage of 20 or $30 \mu \mathrm{V}$ for 10 different colors. The actual printout of a topographic map based upon numbers for a given frequency varies from 0 10, of which 10 represents a total of 20 or $30 \mu \mathrm{V}$ depending upon the scale used. Topographic maps were developed in two different modes, the first of which represents the actual numerical value for different frequencies and the second a color display of the frequency bands. Each of the subject's topographic analysis was available as a printout for the various frequencies as well as a color coded topographic map. In this study the following band widths were used: delta - 1 to $3.9 \mathrm{~Hz}$, theta -4.0 to $7.8 \mathrm{~Hz}, a 1 p h a_{1}-8.0$ to $9.8 \mathrm{~Hz}, a 1 p h a_{2}-10$ to $11.8 \mathrm{~Hz}$, beta -12 to $28 \mathrm{~Hz}$. These band widths and the square root of the power (amplitude) differ slightly from those originally reported in the abstract of this research (Domino and Matsuoka, 1990).

\section{Plasma Nicotine and Cotinine Analys is}

Plasma nicotine and cotinine were determined using the methods described by Hariharan et a1. (1988) and Domino et al. (1992). Approximately $5 \mathrm{ml}$ of venous blood were withdrawn into heparinized tubes immediately before and after tobacco smoking. The plasma was separated and frozen at $-20^{\circ} \mathrm{C}$ until a convenient time for batch analysis.

\section{Data Analysis}

All of the data were organized in a spread sheet format for subsequent statistical analysis. Correlated and non-correlated two-tafled Student " $t$ " tests were used to determine statistical probabilities with $p<.05$.

\section{Results}

\section{EEG Effects}

In most of the volunteers before smoking there was a relative decrease in alpha activity which increased after smoking. This EEG pattern frequently changed after smoking any of the four different cigarettes. There were marked Individual differences. Smoking high nicotine cigarettes tended to increase total EEG alpha activity, as illustrated in the ink tracing in Fig 2. From this raw EEG tracing, it is impossible to determine discrete and subtle EEG changes as might be expected in an awake subject after inhaling tobacco smoke of varying nlcotine content.

A complete analysis of the effects of tobacco smoking on mean \pm S.E. total cortical EEG activity (separated into discrete frequency bands) is summarized in Fig 3 . Interestingly, only after smoking nicotine containing clgarettes was there a mean decrease in alpha $(8.0-9.8 \mathrm{~Hz})$ and an increase in alpha $(10.0-11.8 \mathrm{~Hz})$ amplitude in the EEG. In these subjects there were no consistent mean changes in delta, theta, or beta activity, although some trends were noted, as seen in Fig 3 . Individual differences were marked, irrespective of the nicotine content of the cigarette smoked. 


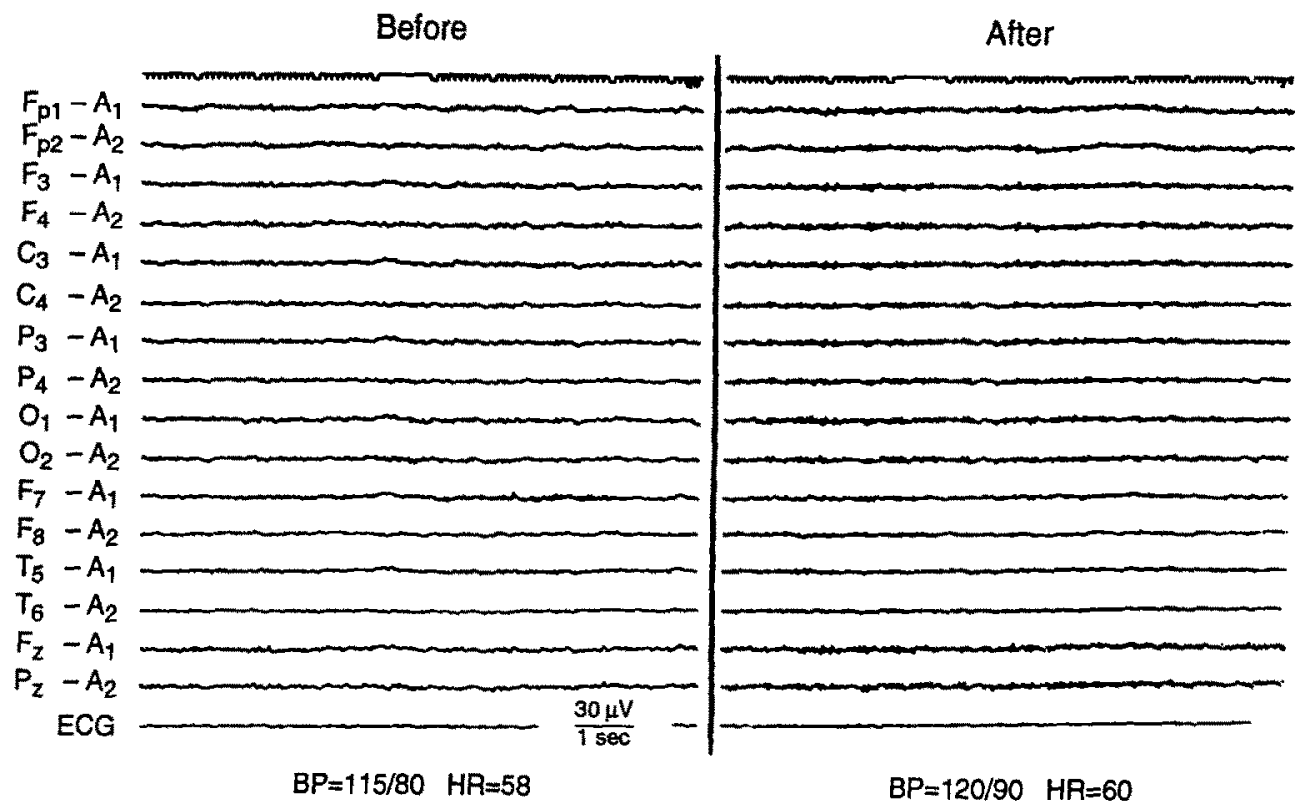

Fig 2. EEG effects of smoking a University of Kentucky high nicotine research cigarette ( $2.16 \mathrm{mg}$ nicotine) in a normal smoker.
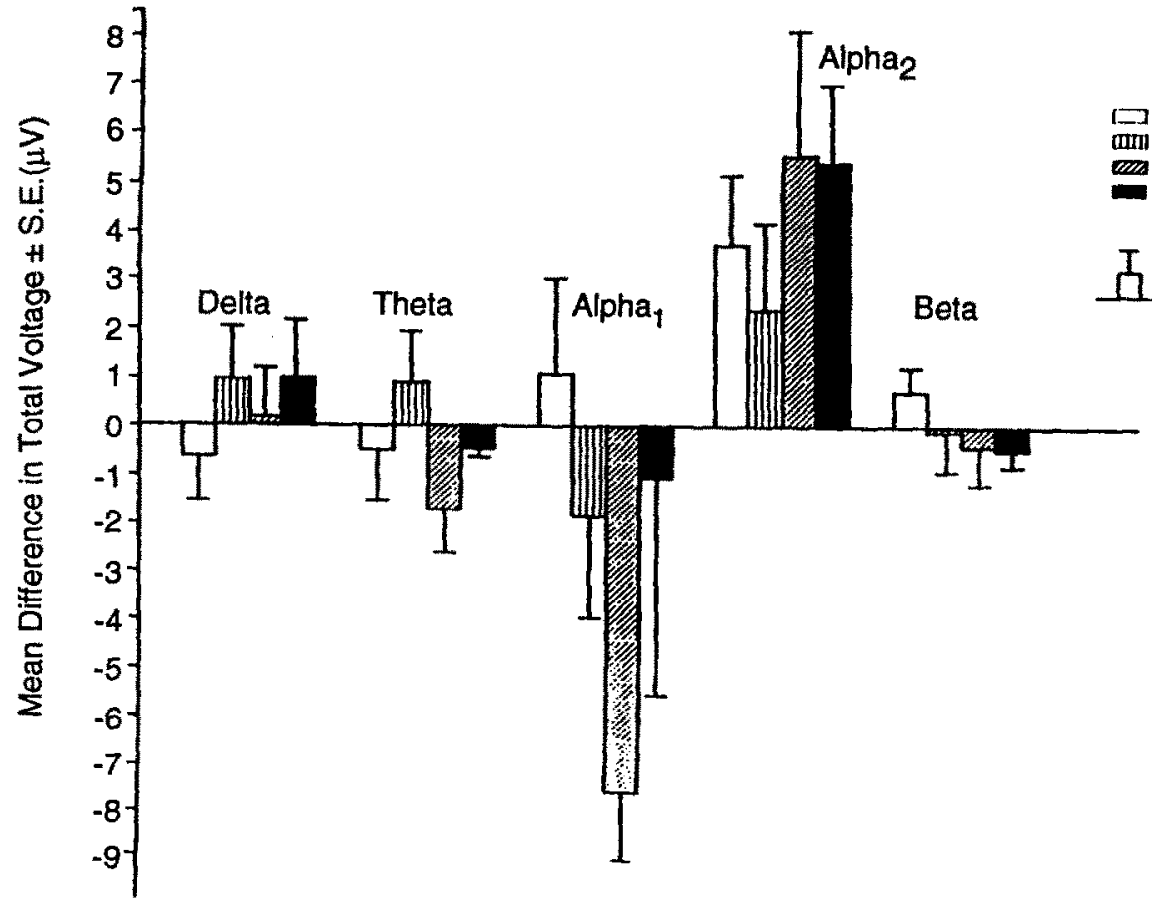

Fig 3. Effects of smoking on total cortical EEG activity. 


\section{Topographic EEG Patterns}

Individual differences also were marked in the topographic EEG patterns irrespective of the nicotine content of the cigarettes smoked. This was especially evident after smoking the zero and low nicotine containing cigarettes. In contrast, after smoking the high nicotine containing cigarettes, more consistent EEG changes were noted.

Two major trends were observed following tobacco smoking. There was a tendency to increase the total distribution of alpha activity in the cerebral cortex, but individual differences were marked. In some subjects, a diffuse increase in alpha $a_{2}$ EEG activity was seen after tobacco smoking. In other subjects, only an increase in alpha EEG activity in the occipital areas was observed after smoking similar tobacco cigarettes. These two patterns are shown in Fig 4 and 5 from two different subjects who smoked the $2.0 \mathrm{mg}$ nicotine commercial cigarettes.

A
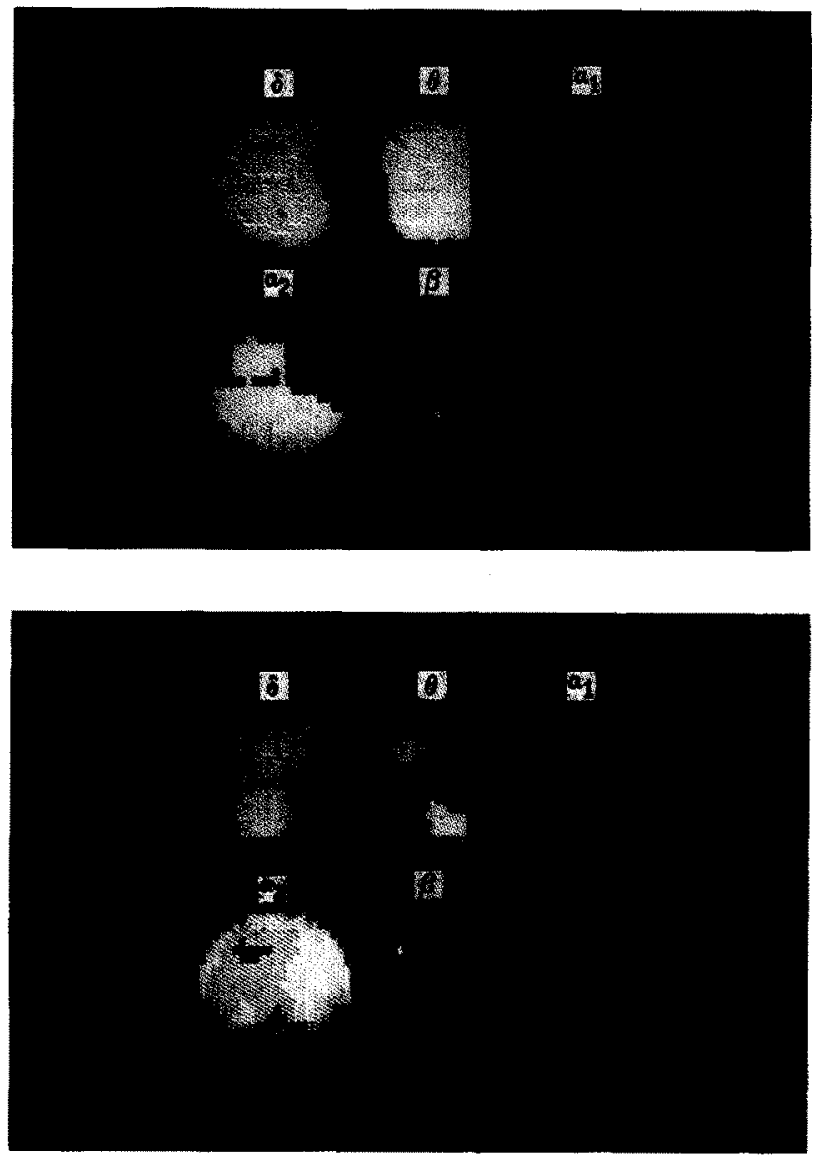

Fig $4 \mathrm{~A}$. Control topographic EEG pattern before tobacco smoking. 4B. Topographic EEG pattern after smoking a high nicotine $(2.0 \mathrm{mg}$ ) cigarette in this subject. The five different EEG bands, $\delta, \theta, \alpha_{1}, \alpha_{2}$, and $B$ are shown color coded in this and the subsequent figure. The marked decrease in $\alpha_{1}$ and the increase in $\alpha_{2}$ activity after tobacco smoking as noted. 
A

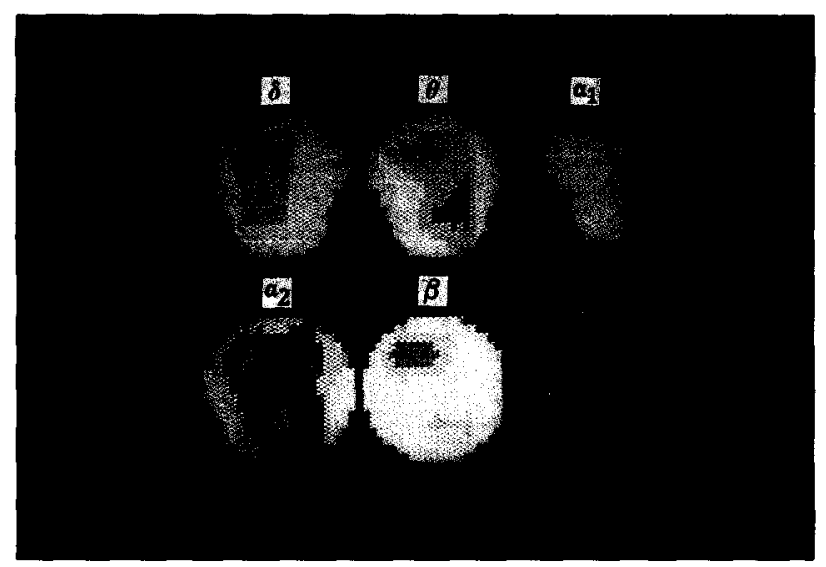

B

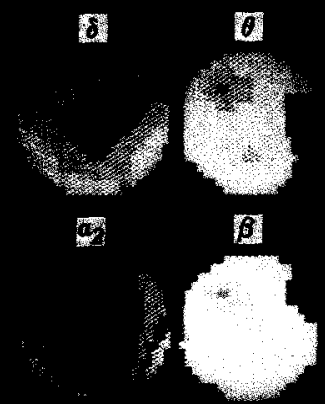

Fig 5 A. Control topographic EEG pattern before tobacco smoking. 5B. Topographic EEG pattern after smoking a high nicotine $(2.0 \mathrm{mg})$ cigarette in a different subject. Note the marked diffuse and more anterior increase in $\alpha_{2}$ activity, etc. in this subject after tobacco smoking.

\section{Cardiovascular Effects}

Heart rate and mean systemic arterial blood pressure were measured as a control for the efficiency of tobacco smoking and the absorption of nicotine. The mean data obtained are illustrated in the bar graphs in Fig 6 . Smoking the nicotine free cigarette produced no increase in mean blood pressure or heart rate. In contrast, smoking any of the nicotine containing cigarettes increased mean blood pressure and heart rate by a small degree.

\section{Plasma Nicotine and Cotinine Levels}

During the course of this study it was noted that the Japanese volunteers who smoked 

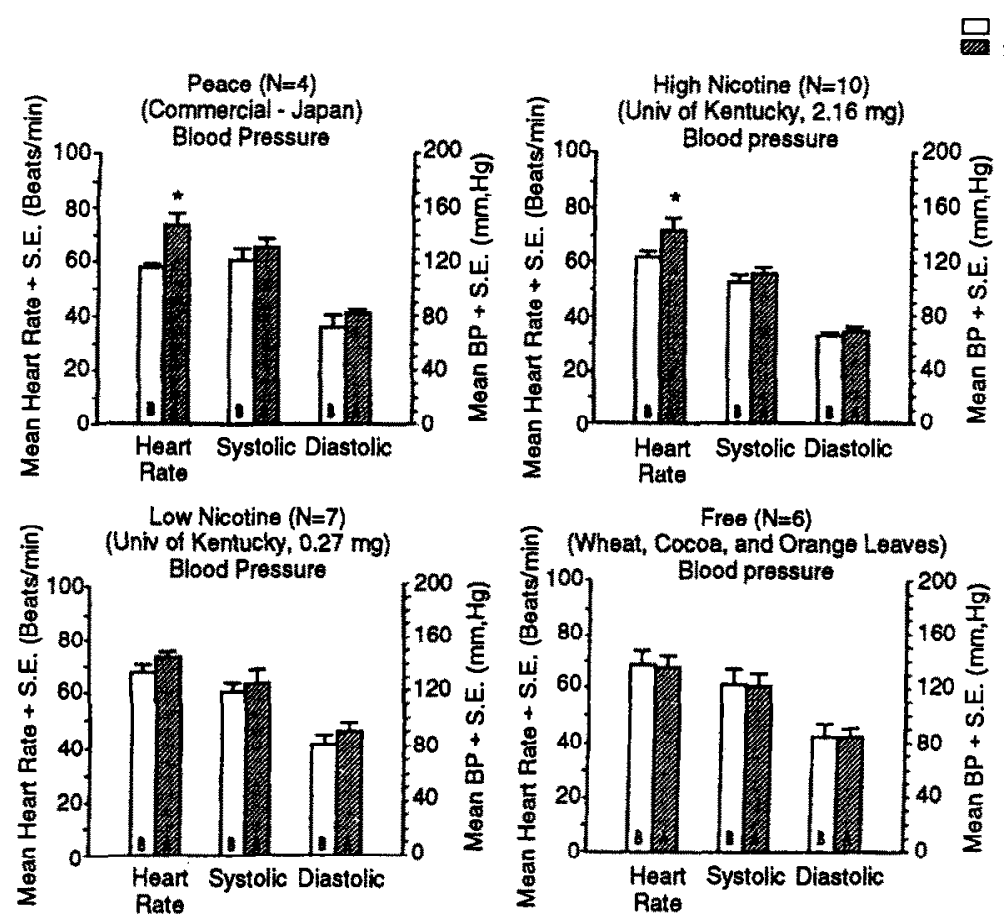

5759

Fig 6. Cardiovascular effects of smoking different nicotine containing cigarettes.

the low as well as the high nicotine cigarettes had relatively small increases in systemic arterial blood pressure and heart rate. Therefore, it was decided to obtain pre- and post-blood samples on the remaining five of seven low and three of ten high nicotine cigarette smokers. The mean \pm S.E. change in plasma nicotine after smoking low nicotine cigarettes was $0.5 \pm 0.1 \mathrm{ng} / \mathrm{ml}$ and only $5.4 \pm 1.2 \mathrm{ng} / \mathrm{ml}$ after swoking the high nicatine cigarettes. The mean \pm S.E. pretobacco smoking cotinine levels for all eight volunteers was $212.1 \pm 48.8$ and $214.1 \pm 51.1 \mathrm{ng} / \mathrm{m} 1$ post-tobacco smoking. There was no difference in cotinine levels pre-post smoking for either the low or high nicotine containing cigarettes. Presmoking plasma cotinine levels ranged from 46.8 to $461.8 \mathrm{ng} / \mathrm{ml}$, Indicating that there was a ten fold variation in the presmoking state. Although the tobacco smokers were asked to stop smoking overnight for an approximate 10-12 hr period of abstinence, there was no independent confirmation that they actually complied. Evidence of noncompliance to this request for abstinence from smoking was noted in the marked range of presmoking plasma levels of nicotine in these eight tobacco smokers from 0 to $25.0 \mathrm{ng} / \mathrm{ml}$ with a mean \pm S.E. of $9.2 \pm 3.4 \mathrm{ng} / \mathrm{ml}$. 


\section{Discussion}

\section{EEG Changes}

This study involving adult male and female Japanese tobacco smokers provides some data which confirms the literature and other data which is unexpected. The expected findings are that tobacco smoking in a nicotine concentration dependent manner alters scalp EEG patterns. The unexpected finding is that even though individual variation is marked, smoking a zero nicotine content cigarette had EEG effects including a slight decrease in total delta and theta, a slight increase in beta, and a definite increase in total alpha (alpha $+a l p h a_{2}$ activity; Fig 3). In contrast, smoking a high nicotine research or commercial cigarette decreased alpha and increased alpha activity. Surprisingly, in this study there was no increase in EEG beta activity after tobacco smoking irrespective of the nicotine content of the clgarette. Smoking any of the four different types of cigarettes which contained $0,0.27,2.0$, and $2.16 \mathrm{mg}$ of nicotine increased total alpha EEG activity. Especially important was the finding that the effects of increasing concentrations of nicotine cannot be distinguished by measuring the total alpha activity. Only by separating the alpha frequency band into alpha and alpha $_{2}$ subgroups were clear cut differences observed. An even greater subdivision of alpha frequencles may lead to even greater differences. Ulett and Itil (1969) showed that after being deprived of tobacco smoking for $24 \mathrm{hr}$ eight heavy smokers had a shift to the left in their power frequency spectrum to a mean peak alpha frequency of 9.5 $\mathrm{Hz}$, whereas their mean peak alpha frequency was $10.5 \mathrm{kz}$ while smoking. Subsequently, Itil et al. (1971) did a more detailed study of 32 male tobacco smokers also using EEG analog power spectral analysis during $24 \mathrm{hr}$ of smoking deprivation and after cigarette smoking. During deprivation there was an increase in EEG power in the 5.5,6.0,6.5, $7.0,8.0$ and $9.0 \mathrm{~Hz}$ bands and a decrease in EEG power in the $11-18 \mathrm{~Hz}$ bands. These EEG changes which occurred during deprivation were reversed after smoking three tobacco cigarettes within $10 \mathrm{~min}$. Similarly, Knott and Venables (1977) reported that nonsmokers had a mean dominant alpha frequency of $10 \mathrm{~Hz}$, while $13.15 \mathrm{hr}$ deprived smokers had a mean dominant alpha frequency of 9.3-9.4 Hz. The dominant alpha frequency of the deprived smokers increased to $9.8 \mathrm{~Hz}$ three to five min and to 10.0 $\mathrm{Hz} 13$ to 15 min after smoking two $1.6 \mathrm{mg}$ nicotine tobacco cigarettes. Subsequently, Knott and Venables (1979) and Knott (1988, 1989, 1991) elaborated on these findings using a variety of EEG techniques including topographic analyses.

\section{Topographic Mapping}

Topographic mapping provides additional information regarding the effects of tobacco smoking that is nicotine concentration dependent. After smoking nicotine containing cigarettes there was a mean increase in alpha $(10.0-11.8 \mathrm{~Hz}$ ) activity in the EEG, not only in the occipital areas but also more diffusely throughout the cerebral cortex. Two major trends were observed following tobacco smoking. There was a tendency to increase alpha activity in the cortex, but individual differences were marked. In some subjects, a diffuse increase in alpha ${ }_{2}$ EEG activity was seen after tobacco smoking. 
In other subjects, only an increase in alpha 2 EEG activity in the occipltal areas was observed after smoking similar tobacco clgarettes. Individual differences were marked, irrespective of the nicotine content of the cigarettes smoked. Baseline state, the nicotine content of the cigarettes smoked, and Individual subject variation, including different smoking patterns, all determine the EBG effects observed. Zero nicotine cigarette smoking also caused EEG changes, including an increase in alpha and alpha activity. No decrease in alpha ${ }_{1}$ activity was noted. The findings in the present study are generally similar to those described by Domino et al. (1992) using Caucasian tobacco smokers.

\section{Cardiovascular Effects}

In contrast to smoking a zero nicotine cigarette, the cardiovascular effects of tobacco smoking include a slight increase in heart rate, systolic, and diastolle blood pressure.

\section{Conclusions}

Baseline state, Individual subject variation, and the nicotine content of the cigarettes smoked determine the EEG effects observed. After tobacco smoking. the topographic distribution of EEG frequencles reveals a diffuse increase in alpha activity which is greatest in those smoking a high nicotine cigarette. Zero nicotine cigarette smoking also causes EEG changes but not a decrease in alpha, and an increase in alpha $a_{2}$ activity.

The cardiovascular changes of tobacco smoking result in an increase in heart rate, systolic and diastolic blood pressure in contrast to smoking a zero nicotine cigarette.

\section{Acknowledgement}

The authors would like to acknowledge the efforts of Tadahiro Ishikawa in this study. Supported in part by NIDA Grant DA-07226.

\section{References}

DOMINO, E.F. and MATSUOKA, S. (1990) Effects of tobacco smoking on the topographic EEG. Brain Topography 3; 248-250.

DOMINO, E.F., HARIHARAN, M., VAN NOORD, T, and DEMANA, T. (1992) Current experience with HPLC and GC-MS analyses of nicotine and cotinine, Med. Sci. Res. 20; 859-860.

EDWARDS, J.A. and WARBURTON, D.M. (1982) Smoking, nicotine, and electrocortical activity. Pharmaco1. and Therap. 19: 147-164.

HARIHARAN, Y., VAN NOORD, T. and GREDEN, J.F. (1988) A high-performance liquidchromatographic method for routine simultaneous determination of nicotine and cotinine. Cilin. Chem. 34: 724-729.

ITIL, T.M., ULETT, G.A., HSU, W., KLINGENBERG, H. and ULETT, J.A. (1971) The effects of smoking withdrawal on quantitatively analyzed EEG. Clin. Electroencephalog. 2: 44-51.

KNOTT, V.J. (1988) Dynamic EEG changes during cigarette smoking. Neuropsychobiol. 19: $54-60$. 
KNOTT, V.J. (1989) Brain electrical imaging the dose-response effects of cigarette smoking. Neuropsychobiol. 22: 236-242.

KNOTT, V. (1991) Neuroelectric correlates of smoking behavior. In: Effects of Nicotine on Biological Systems, F. Adlkofer and K. Thurau (Eds.), Pp. 491-550, Advances in Pharmacological Sciences, Birkhauser Verlag Basel.

KNOTT, V.J. and VENABLES, P.H. (1977) EEG alphe correlates of non-smokers, smokers, smoking, and smoking deprivation. Psychophysiol. 14: 150-156.

KNOTT, V.J. and VENABLES, P.H. (1979) EEG alpha correlates of alcohol consumption in smokers and nonsmokers. Effects of smoking and smoking deprivation. J. Studies on Alcohol 40: 247-257.

MATSUOKA, S., MIZOGUCHI, T. and UENO, S. (1979) Pathological studies on the EEG abnormalities in patients with CNS disease with special reference to computer topographic display of delta wave. J. UOEH (Japan) 1: 297-338.

Surgeon General's Report: (1988) The Health Consequence of Smoking: Nicotine Addiction, pp. 1-639, U.S. Department of Health and Human Services, Washington, D.C.

ULETT, J.A. and ITIL, T.M. (1969) Quantitative electroencephalogram in smoking and smoking deprivation. Science 164: 969-970.

UENO, S., MATSUORA, S., MIZOGUCHI, T., NAGASHIMA, M. and CHENG, C.L. (1975) Topographic computer display of abnormal EEG activities in patients with CNS diseases. Memoirs Faculty Eng. Kyushu Univ. (Japan) 34: 195-209.

Inquiries and reprint requests should be addressed to:

Dr. E.F. Domino

Department of Pharmacology

The University of Michigan

6322 Medical Science Building

Ann Arbor, Michigan 48109-0626

U.S.A. 